\title{
Pseudomonas gessardii-A novel pathogenic bacterium associated with the cases of corneal ulcers and producing virulent pyoverdine pigment
}

\author{
Deepika Jain* \\ Department of Microbiology, Ghulam Nabi Azad Arts, Commerce and Science College, Barshitakli, Dist-Akola, Maharashtra, India.
}

\section{ARTICLE INFO \\ Article history: \\ Received on: May 05, 2021 \\ Accepted on: August 19, 2021 \\ Available Online: February 15, 2022}

\section{Key words:}

Bacterial corneal ulcer,

Pseudomonas gessardii, genotypic identification, antibiotic sensitivity and resistance pattern, pyoverdine, pigment extraction

\begin{abstract}
Bacterial corneal ulcer (BCU) is an infection that results into loss of vision (approx. 10\%) and blindness. $\mathrm{BCU}$ requires constant attention since antibiotic treatment failure due to genetic alteration is common in microorganisms but the present study confirms that the ineffective treatment of corneal blindness is due to this novel bacterium. Around 300 corneal scrapings were performed in patients presenting with corneal ulcers from ophthalmology hospitals, government hospitals, and clinical laboratories of different places in Maharashtra, India. The novel pathogenic bacterium, i.e., Pseudomonas gessardii, was isolated from corneal ulcer samples from patients and identified using molecular characterization. The most common risk factors associated with $\mathrm{BCU}$ are contact lens and trauma. The pathogen produces a pyoverdine pigment, nitric oxide scavenger, exhibiting antioxidant activity. The novel bacterium is sensitive to the fluoroquinolones group of antibiotics and tobramycin. It is necessary to diagnose corneal ulcers at an early stage to reduce the probability of permanent loss of eye sight and corneal structural damage.
\end{abstract}

\section{INTRODUCTION}

The human eye is a sensory organ. The vision depends on the clarity of the cornea $[1,2]$. Corneal ulcer is considered to be the primary causative agent of loss of vision $(10 \%)[2,3]$. "Corneal ulcer is defined as the loss of corneal layers due to infection and formation of raw, scoop out area [4]."

Bacteria, fungi, viruses, parasites, or remote infections in the body account for the cause of corneal ulcers $[5,6]$, and bacterial corneal ulcers (BCU) account for nearly $65 \%-90 \%$ of the infections. Tears and corneal scratches pave way for the entrance of bacteria resulting in an infection. Staphylococcus aureus, Streptococcus pneumoniae, Escherichia coli, Enterococci, Pseudomonas, Klebsiella, Proteus, Bacillus cereus, and many other bacteria are reported to cause corneal ulcers $[2,5,7-10]$.

The present study highlights the isolation of a novel bacterium from the corneal ulcer samples. The article focuses on the virulence

\footnotetext{
*Corresponding Author

Deepika Jain, Department of Microbiology, Ghulam Nabi Azad Arts, Commerce and Science College, Barshitakli, Dist-Akola, Maharashtra, India.E-mail address: deepika19jain@gmail.com
}

factors and provides information on the primary treatment with appropriate antibiotics to control the loss of vision.

\section{MATERIALS AND METHODS}

\subsection{Sample Collection}

A regular procedure was followed for the collection of samples, such as Bard-Parker surgical blade for corneal scratches and broth moistened cotton swabs for rubbing the lid margin of the infected cornea [2]. Specimens were transferred into containers with nutrient broth and were transported directly to the laboratory. A total of 300 samples were collected from the Government Medical College (GMC), ophthalmic hospitals, and clinical laboratories of the several districts and cities of Maharashtra, India. The hospitals were selected based on the sample availability, geographical proximity, and feasibility of conducting the study $[2,6,10]$.

\subsection{Sample Enrichment}

Samples were collected in sterile tubes. Each tube contained $0.5 \mathrm{ml}$ of Brain Heart Infusion broth for enrichment and these tubes were transferred directly to the laboratory. Sample tubes were incubated for 24 hours at $37^{\circ} \mathrm{C}[2,6,9]$. 


\subsection{Phenotypic Isolation}

All enriched cultures were streaked on cystine lactose electrolyte deficient agar and nutrient agar (NA) plates under aseptic conditions. All agar plates were incubated at $37^{\circ} \mathrm{C}$ for 24 hours. Colonies were selected based on morphological characteristics such as size, shape, margin, texture, opacity, elevation, Gram's nature, color, and inoculated on selective media such as cetrimide agar and Pseudomonas isolation agar. Agar plates were incubated at $37^{\circ} \mathrm{C}$ for 24 hours, post-inoculation. On the following day, biochemical tests were carried out $[2,6,11,12,13]$.

\subsection{Genotypic Isolation}

According to Jain and Kamble's [2] research methodology, 16S rRNA analysis was carried out for molecular characterization by using InstaGeneTM Matrix for DNA extraction, MJ Research Peltier Thermal Cycler for amplification and ABI PRISM ${ }^{\circledR}$ BigDyeTM Terminator Cycle Sequencing Kits with AmpliTaq ${ }^{\circledR}$ DNA polymerase for sequence reactions.

\subsection{Antibiotic Sensitivity Test}

The antibiotic sensitivity and resistance of the isolated bacterium were analyzed by agar disk diffusion technique using MuellerHinton agar $[2,14,15]$. The antibiotics used are explained below.

\subsection{1. $\beta$-lactam group of antibiotics}

2.5.1.1. Penicillins. Amoxicillin ( $10 \mathrm{mcg}$ ), amoxyclav (amoxicillin $20 \mathrm{mcg}$ and clavulanic acid $10 \mathrm{mcg})(30 \mathrm{mcg})$, ampicillin $(10 \mathrm{mcg})$, methicillin $(10 \mathrm{mcg})$, and penicillin $\mathrm{G}(10 \mathrm{mcg})$.

2.5.1.2. Cephalosporins. Cefalexin $(30 \mathrm{mcg})$, cefixime $(30 \mathrm{mcg})$, cefpodoxime (30 mcg), ceftazidime (30 mcg), cefotaxime (30 mcg), cephazolin $(5 \%)$, cefadroxile $(30 \mathrm{mcg})$, and ceftriaxone $(30 \mathrm{mcg})$.

2.5.1.3. Carbapenems. Imipenem $(10 \mathrm{mcg})$ and Meropenem (10 mcg).

\subsubsection{Non- $\beta$-lactam group of antibiotics}

2.5.2.1. Tetracycline. Tetracycline $(30 \mathrm{mcg})$ and chloramphenicol (30 mcg).

2.5.2.2. Aminoglycosides. Bacitracin ( $30 \mathrm{mcg})$, kanamycin (20 mcg), gentamicin (10 mcg), erythromycin $(15 \mathrm{mcg})$, tobramycin $(1.33 \%)$, and vancomycin $(30 \mathrm{mcg})$.

2.5.2.3. Fluoroquinolones. Ofloxacin $(5 \mathrm{mcg})$ and moxifloxacin $(0.5 \%)$.

2.5.2.4. Quinolones. Ciprofloxacin $(10 \mathrm{mcg})$ and norfloxacin $(10 \mathrm{mcg})$.

\subsubsection{Combination therapy}

Ceftazidime + Ciprofloxacin, Cephazolin + Vancomycin, Cephazolin + Tobramycin, and Gentamicin + Cefuroxime.

\subsection{Pigment Extraction and Its Assessment as a Virulent Factor}

The present study utilized the pigment extraction technique mentioned in Jain and Kamble's [16] and Shatila et al.'s [17] studies.

\subsection{Fourier Transform Infrared Spectroscopy (FTIR) for Pigment Identification}

The quality of pigments was analyzed using Fourier transform infrared spectroscopy (FTIR). FTIR spectrophotometer is perhaps the most powerful tool for identifying the types of chemical bonds (functional groups) present in compounds. The wavelength of light absorbed is characteristic of the chemical bond as can be seen in the annotated spectrum. By interpreting the infrared absorption spectrum, the chemical bonds in a molecule can be determined.

\subsection{Nitric Oxide (NO) Scavenging Activity Assay}

The scavenging activity assay was carried out using methods by Jain and Kamble [16], Awah et al. [18], Parul et al. [19], and Iheanyichukwu et al. [20]. The chemicals used were sodium nitroprusside $(10 \mathrm{mM})$, methanol and Griess reagent ( $1 \%$ sulfanilamide in $5 \%$ phosphoric acid and $0.1 \%$ naphthyl ethylenediamine dihydrochloride).

\subsection{Antioxidant Activity Assay}

The percentage inhibition of the extract was evaluated and recorded using the following formula [18-20]:

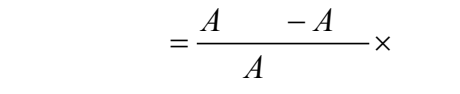

where $A_{\text {control }}=$ absorbance of control sample and $A_{\text {test }}=$ absorbance in the presence of the samples of extracts.

\subsection{Statistical Analysis}

Statistical analysis was carried out by Statistical Package for the Social Sciences software. Analysis of variance (ANOVA) test (using the number of independent variables in one way and two ways) significance levels were also determined.

\section{RESULTS}

A total of 212 samples were found to be positive for bacterial isolation. In the present study, $61 \%$ of the patients were from urban areas and 39\% were from rural areas. The chief frequency was established between 31 and 40 years of age. Males reported to be at maximum risk of contracting the infection. $36.17 \%$ of the patients had severe infection, $29.25 \%$ had moderate infection, and $34.57 \%$ had mild infection. The prime risk factors were contact lens $(32 \%)$ and trauma (21\%).

A total of 278 types of bacteria were isolated from 212 positive specimens. Six isolates confirmed the presence of Pseudomonas gessardii (coded as PBCUUn101). PBCUUn101 is a motile Gramnegative coccobacilli. They exhibit greenish yellow colonies on cetrimide agar and Pseudomonas isolation agar, and green colored colonies on NA. These isolates degraded starch and DNA by producing amylase and DNase enzyme, respectively. PBCUUn101 isolate fermented glucose and mannitol. They were also catalase, caseinase, gelatinase, oxidase, and nitrate reductase positive.

For accuracy, 16S rRNA molecular characterization was carried out for those unknown six isolates using Muscle 3.7 program [21]. 
The phylogenic tree showed 100\% similarity between PBCUUn 101 and $P$. gessardii strain SSB7 (JX042465.1) (Fig. 1).

The 16S rRNA genome sequence of $P$. gessardii and Gram-negative short rods isolated from the patients has been deposited at the National Center for Biotechnology Information (NCBI) GenBank sequence database under accession numbers LC217385.

Vancomycin, tetracycline, bacitracin, and erythromycin were ineffective on $P$. gessardii. The fluoroquinolone group of antibiotics and tobramycin were effective against this novel bacterium (Fig. 2).

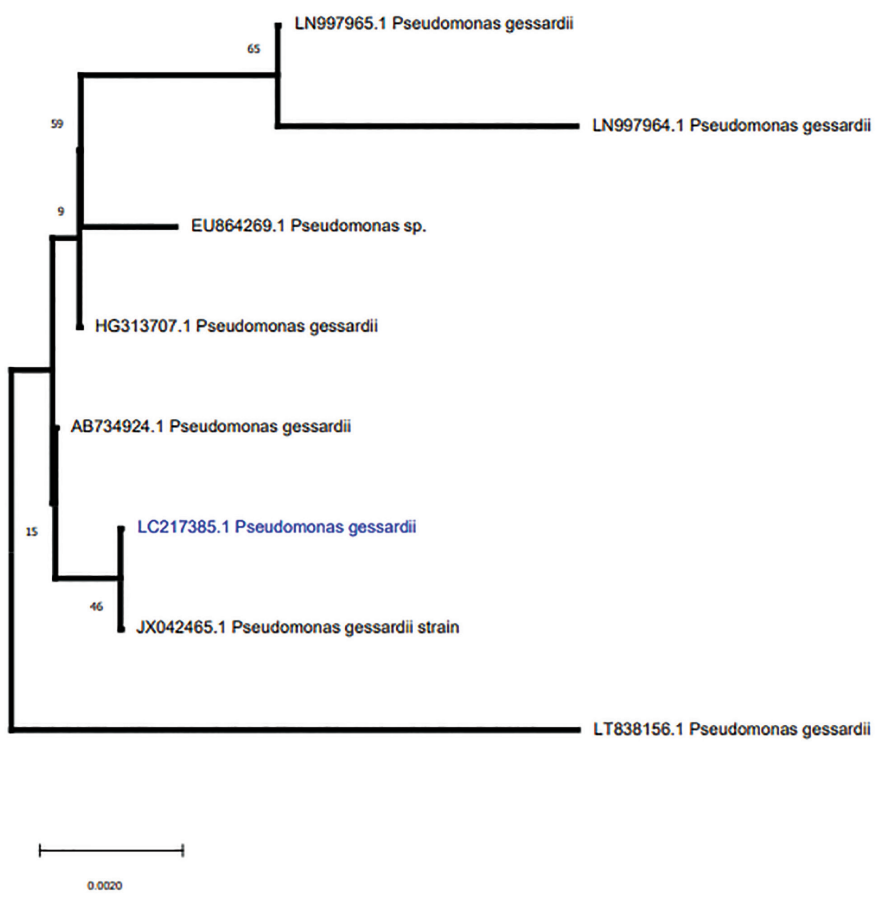

Figure 1: Phylogeny of $P$. gessardii (PBCUUn101).
Pseudomonas gessardii is resistant to amoxicillin, ampicillin, methicillin, penicillin $\mathrm{G}$, and cefotaxime. Ceftriaxone and the carbapenem group of antibiotics, such as imipenem and meropenem, were $70 \%-82 \%$ effective (Fig. 3). Pseudomonas gessardii exhibited $80 \%-100 \%$ sensitivity toward all the combinations (Fig. 4).

In the present study, $P$. gessardii was found to be a novel bacterium compared to other reported corneal ulcer bacteria. This is a pioneer study to establish the same. Virulence factor, also studied, is a mechanism for their endurance. Greenish pigment produced by $P$. gessardii may be one of the mechanisms for virulence which may increase the potential of bacteria to cause the disease. The extracted pigment was characterized using FTIR spectroscopy by studying their structural and functional groups and peaks (Fig. 5). Pseudomonas gessardii produced pyoverdine pigment.

\subsection{Scavenging Activity of Pyoverdine Pigment}

$\mathrm{NO}$ has a robust $\mathrm{NO}+$ nature when it is released from sodium nitroprusside [20]. Significant NO scavenging activity was exhibited by pyoverdine pigments produced by $P$. gessardii. The NO scavenging magnitude depends on pigment concentration [20]. In this study, the most significant scavenging was observed at $100 \mu \mathrm{g} / \mathrm{ml}$ concentration which was due to pyoverdine pigment's vigorous activity (Table 1).

\subsection{Antioxidant Activity}

The pyoverdine pigment extract's \% inhibition was calculated and recorded. The inhibition of NO depends on the concentration of the pigment. As the absorbance decreases, the concentration of the pigment and \% inhibition increases exponentially (Fig. 6).

\section{DISCUSSION}

BCU is an infection of the corneal stroma which leads to loss of vision with severe pain and redness. It has to be treated

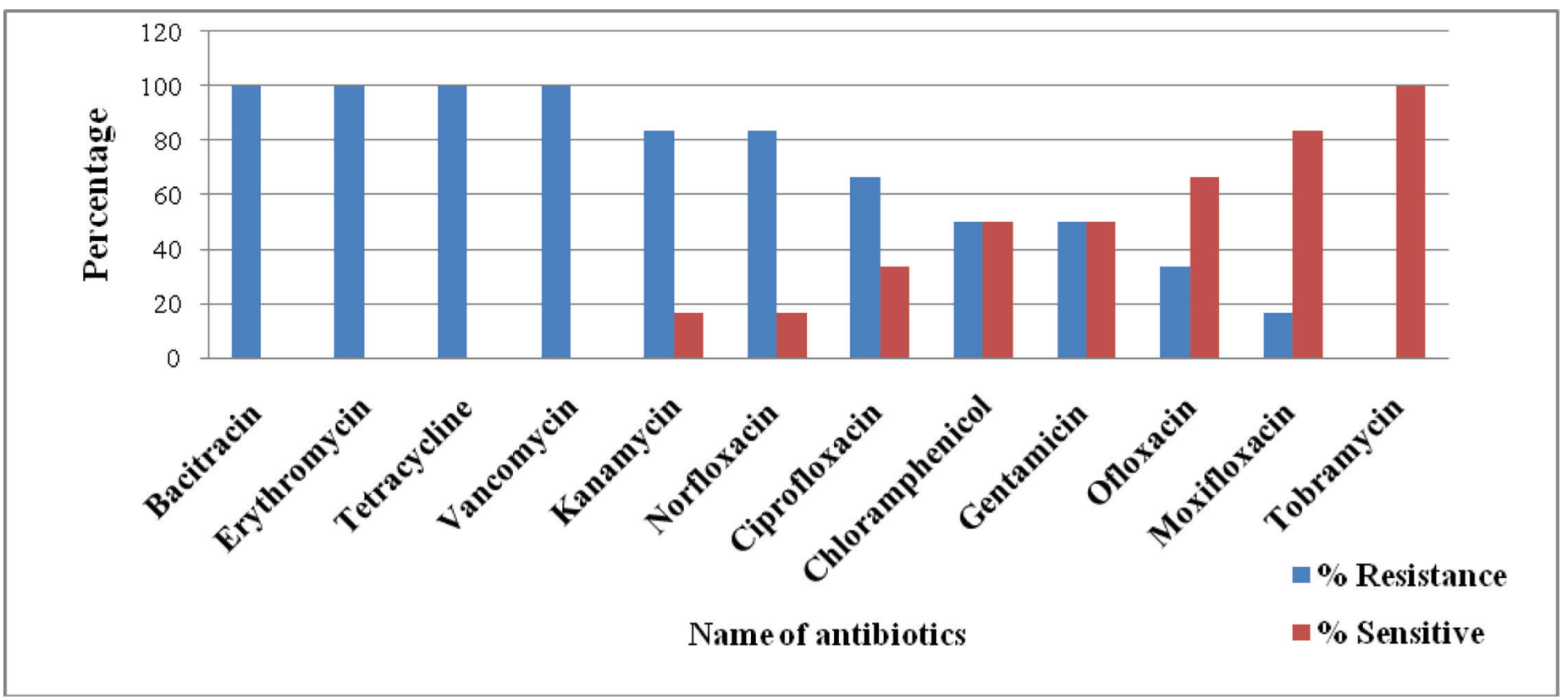

Figure 2: Percentage resistance and sensitivity pattern of $P$. gessardii against the non- $\beta$-lactam group of antibiotics. 
immediately to prevent loss of vision. The cornea ulcer has now been acknowledged as a "silent epidemic".

In this study, the selected patients belonged to both sex groups, varying from 11 to 80 years in age from rural and urban areas. The highest prevalence of BCUs was found to be in the patients aged 31-40. In 1999, Panda et al. [22] had also reported patients of this age group.

Men (54\%) were more prone to corneal ulcers then women (46\%). The male-to-female ratio was found to be 1.18:1. The current ratio was near to $1.6: 1$, whereas a ratio of 1.9:1 was reported by other studies [23-25]. The etiological factors were use of contact lenses and traumatic conditions.

In previous studies, various bacteria such as $S$. aureus, $P$. aeruginosa, Klebsiella, and many more were reported for corneal ulcers [6]. Pseudomonas gessardii isolate was not noted before as per the available literature. In this research, with the rate of $02.15 \%$, these new unknown bacteria isolated was labeled as PBCUUn101 for the present study.

The 16S rRNA sequence analysis is essential to identify the organism because it gives accurate results. In 2011, Daroy et al.

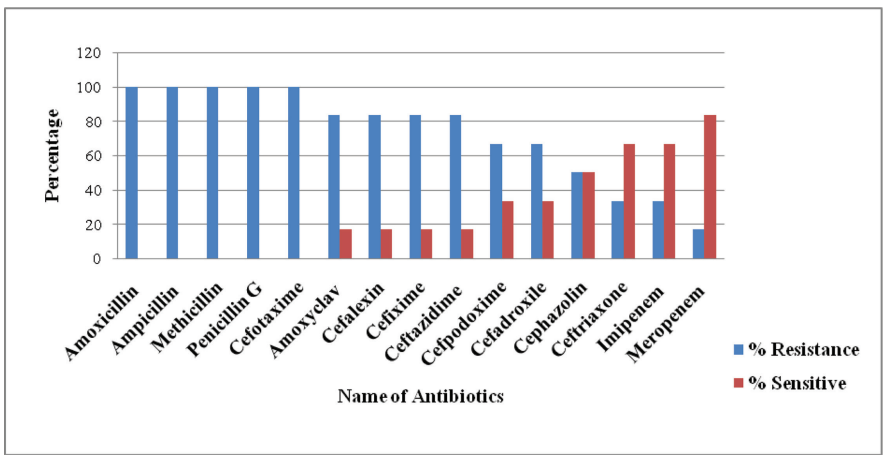

Figure 3: Percentage resistance and sensitivity pattern of $P$. gessardii against the $\beta$-lactam group of antibiotics.
[26] tested 99 ocular samples of patients with clinically suspected eye infections. They found 24 positive samples and identified Pseudomonas aeruginosa, Streptococci, and Enterobacteriaceae. They misidentified some isolates such as Burkholderia cepacia by biochemical tests which were later corrected as Ralstonia mannitolilytica by $16 \mathrm{~S}$ rRNA sequence analysis [26]. After 16S rRNA analysis, PBCUUn101 was confirmed as $P$. gessardii in the present work. This bacterium is novel for corneal ulcers cases. It belongs to the fluorescens group of organisms.

In the current study, $P$. gessardii exhibited significant resistance against aminoglycoside group of antibiotics, followed by the quinolone group, tetracycline, and cephalosporin. These bacteria resisted the $\beta$-lactam group antibiotics by producing the $\beta$-lactamase enzyme. The highest extended spectrum of $\beta$-lactamase production was also observed. However, combination therapy such as ceftazidime + ciprofloxacine and cephazolin + tobramycin was found to be significantly effective.

Pigments extracted from microorganisms exist in various advantageous properties, viz. gene manipulation occurs quickly, easy propagation and wide strain selection can do. On the other hand, they may exhibit virulence in bacteria. Pathogens survive for long term in abscesses, immune cells, and invasiveness due to pigment production $[27,28]$.

Antibiotic resistance is due to pigment production. [29]. Pyoverdines are fluorescent siderophores which are significant virulence factors.

Table 1: Absorbance with $\% \mathrm{NO}_{2}$ scavenging activity of pyoverdine pigment.

\begin{tabular}{ccc}
$\begin{array}{c}\text { Concentration } \\
(\boldsymbol{\mu g} / \mathbf{m l})\end{array}$ & $\begin{array}{c}\text { Optical density at } \\
\mathbf{5 4 6} \mathbf{~ n m}\end{array}$ & \% $\mathbf{N O}^{2}$ scavenged \\
0 & 4.56 & 0 \\
25 & 4.05 & 11.18 \\
50 & 3.45 & 24.34 \\
100 & 1.08 & 71.92 \\
\hline
\end{tabular}

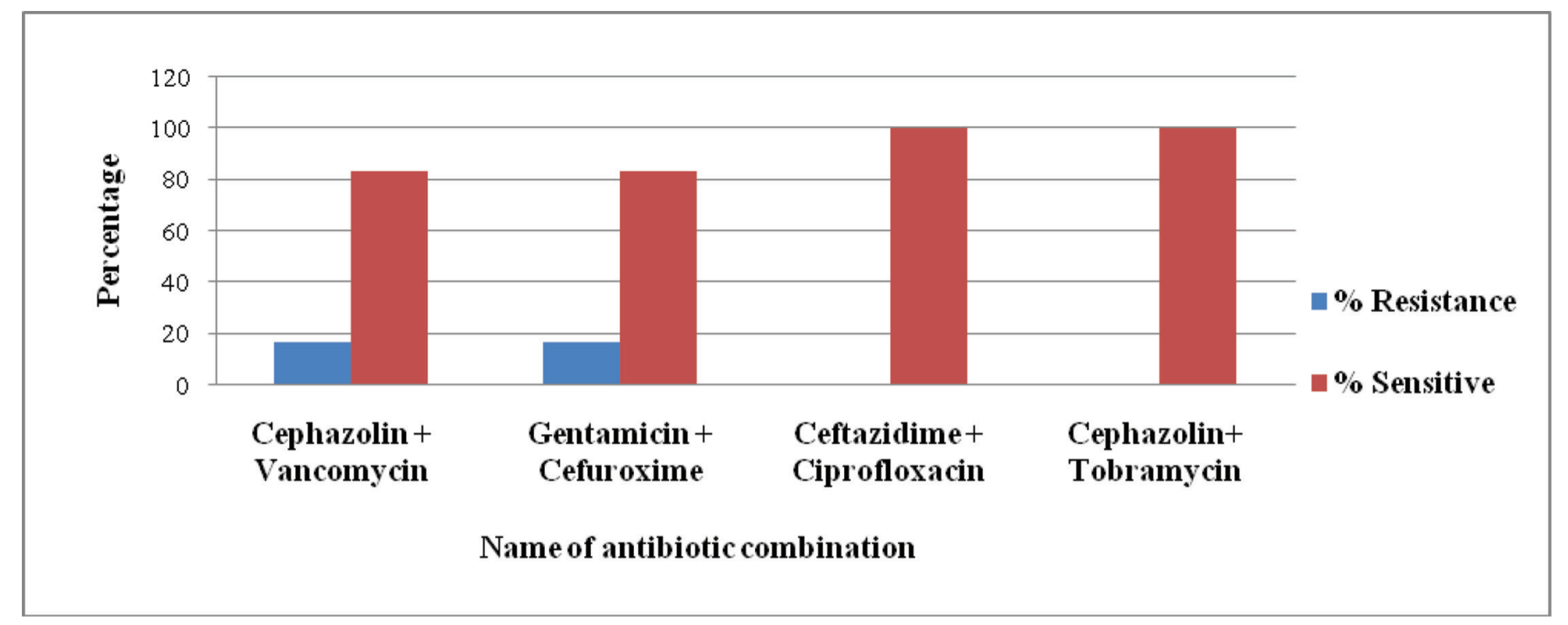

Figure 4: Resistance and sensitivity pattern (percentage) of $P$. gessardii against combination therapy (cephalosporins, aminoglycosides and quinolones group of antibiotic combinations) 


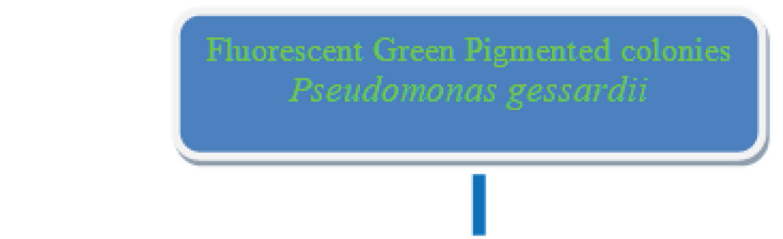

Extraction of pigment in Methanol from cultivated colonies

\section{FTIR Spectroscopy}

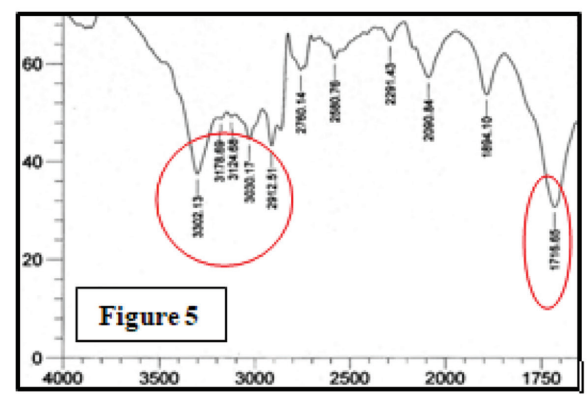

$3302(\mathrm{OH}), 3178-3124$ (N-H), 3030

(Ar-CH), 2912 (Ali-CH) $1716(\mathrm{C}=\mathrm{O})$

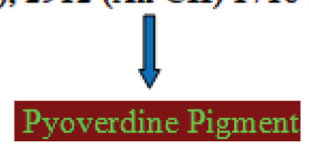

Figure 5: FTIR spectroscopy of Pseudomonas gessardii pigment.

They chelate iron which is essential for the regulation of exotoxin A and protease endoprotease, lysyl class (PrpL) virulence factors to the bacterial cell. They also contribute to biofilm formation [30,31]. A paradoxical pro-oxidant property was exhibited by Pseudomonas pigment. A zwitterion can easily penetrate biological membranes. The pigment can directly accept electrons from reducing agents, such as nicotinamide adenine dinucleotide phosphate (NADPH) and reduced glutathione, then transfer the electrons to oxygen to generate reactive oxygen species, such as hydrogen peroxide and singlet oxygen, at the expense of host antioxidant systems, such as glutathione and catalase [28].

Antioxidants play a significant role in scavenging and inhibiting free radicals. In the present study, it was observed that scavenging activity increases with the concentration of pigment [32].

In this study, the two-way ANOVA test was used. The $p$-value was found to be 0.005 which is less than 0.01 . This result indicates that there is a considerable difference, i.e., antibiotic resistance was not because of the variety of organism but the virulence factors responsible for its antibiotic resistance. Imipenem and meropenem were significantly effective. It was also compared from the $\mathrm{p}$-value that there is no connection between organism number and severity of ulcers ( $p$-value was found to be 0.115 which was more significant than 0.05 ).

\section{CONCLUSION}

Initially, it was assumed that the failure of antibiotic treatment was due to the genetic alteration in typical microflora but the

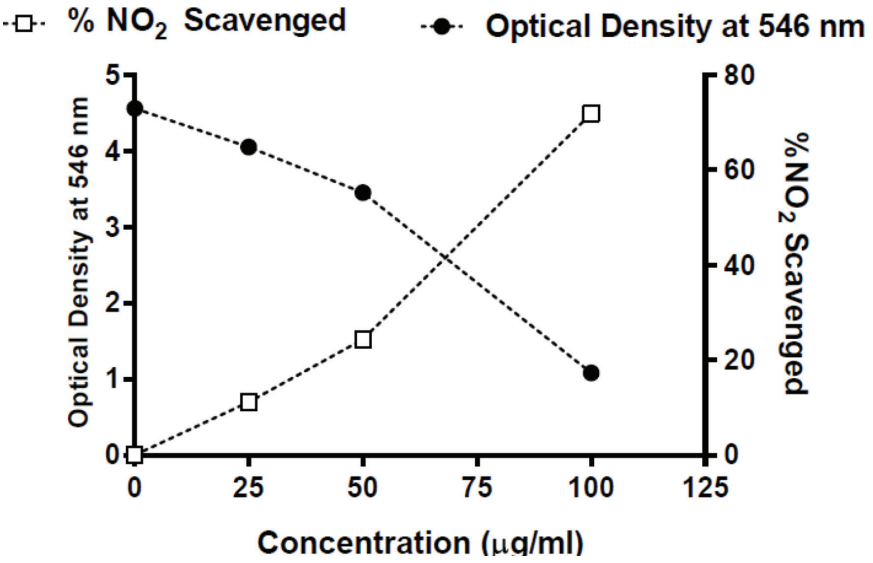

Figure 6: Absorbance and $\% \mathrm{NO}_{2}$ scavenging activity of pyoverdine pigment.

present study confirmed that the ineffectiveness in the treatment of $10 \%$ corneal blindness was due to the novel bacterium $P$. gessardii. Furthermore, monotherapy was not adequate to combat this bacterium. Combination therapy was highly effective against this pathogen in comparison to $\beta$-lactam and non- $\beta$-lactam drugs employed in current use. This study will be helpful for therapeutic management of corneal ulcers.

The present study will contribute to the public awareness among the rural and urban population by enriching them with the essential information pertaining to corneal ulcer since this infection has become extremely prominent leading to blindness in India. A researcher has facilitated the study with the intervention to enhance different measures to prevention, which is the one of the most powerful tools or interventions to eliminate preventable eye problems in the Global Action Plan 2019 and VISION 2020: The Right to Sight.

Accession Number at NCBI Gene bank: LC217385 (P. gessardii).

\section{ACKNOWLEDGMENT}

The authors acknowledge the guidance and support of Dr. Vilas Kamble, Former Head and Professor, Department of Microbiology, Aadarsh College, Dhamangaon Rly, District-Amravati.

\section{AUTHOR CONTRIBUTIONS}

All authors made substantial contributions to conception and design, acquisition of data, or analysis and interpretation of data; took part in drafting the article or revising it critically for important intellectual content; agreed to submit to the current journal; gave final approval of the version to be published; and agree to be accountable for all aspects of the work. All the authors are eligible to be an author as per the international committee of medical journal editors (ICMJE) requirements/guidelines.

\section{CONFLICTS OF INTEREST}

The authors report no financial or any other conflicts of interest in this work.

\section{ETHICAL APPROVAL}

To conduct this study, ethical clearance was obtained for sample collection from the Government Medical College and Hospital 
with outward number 328 and Damani Eye Hospital with outward number 2409.

\section{REFERENCES}

1. Bharathi MJ, Ramakrishnan R, Vasu S, Meenakshi, Palaniappan R. Aetiological diagnosis of microbial keratitis in south India-a study of 1618 cases. Indian J Med Microbiol 2002;20(1):19-24.

2. Jain DN, Kamble VA. Molecular characterization of corneal ulcers causing Staphylococcus aureus. Int J Res Med Sci 2017;5(4):1419-24.

3. Ninama GL, Damor JR, Padhiyar NG, Javadekar TB. To study the causative organism responsible for corneal ulcer in S.S.G Hospital Vadodara, Gujarat. Natl J Commun Med 2011;2(2):237-40.

4. Chatterjee BM. Hand book of ophthalmology. 4th edition, CBS publication, Shahdara, Delhi, 1988.

5. Garg PG, Rao GN. Corneal ulcer: diagnosis and management. Commun Eye Health 1999;12(30):21-3.

6. Jain DN, Musaddiq M. Pathogenic bacteria associated with cases of corneal ulcers. Indian J Life Sci 2014;4(1):21-3.

7. Constantinou M, Daniell M, Snibson GR, Vu HT, Taylor HR. Clinical efficacy of moxifloxacin in the treatment of bacterial keratitis: a randomized clinical trial. Ophthalmology 2007;114(9):1622-9.

8. Manikandan P, Selvam KP, Shobana CS, Ravikumar K, Rajaduraipandi $\mathrm{K}$, Narendran $\mathrm{V}$, et al. Corneal ulcer of bacterial and fungal etiology from diabetic patients at a tertiary care eye hospital, Coimbatore, South India. Med Biol 2008;15(2):59-63.

9. Kaye SB, Rao PG, Smith G, Scott JA, Hoyles S, Morton CE, et al. Simplifying collection of corneal specimens in cases of suspected bacterial keratitis. J Clin Microbiol 2003;41(7):3192-7.

10. Michael Miller J (ed.). A guide to specimen management in clinical microbiology. 2nd edition, American Society for Microbiology, Washington, DC, 1999.

11. Versalovic J (ed.). Manual of clinical microbiology. 10th edition, Washington, DC, American Society for Microbiology, 2011.

12. Bharathi MJ, Ramakrishnan R, Shivakumar C, Meenakshi R, Lionalraj D. Etiology and antibacterial susceptibility pattern of communityacquired bacterial ocular infections in a tertiary eye care hospital in south India. Indian J Ophthalmol 2010;58(6):497-507.

13. Krieg NR, Holt JG. Bergey's manual of systematic bacteriology. 2nd edition, Dordrecht: Springer, 1984.

14. Bauer AW, Kirby WMM, Sherris JC, Turck M. Antibiotic susceptibility testing by a standardized single disk method. Am J Clin Pathol 1966;45(4):493-6.

15. Central Laboratory Standard Institute (CLSI). Performance standards for antimicrobial disc susceptibility tests, approved standards. 10th edition, CLSI document M02. vol. A10, Wayne, PA 19087, USA, 2015.

16. Jain D, Kamble V. Exiguobacterium aurantiacum virulent pigment producing a novel pathogenic bacteria associated with cases of corneal ulcers. Indian J Microbiol Res 2020;5(4):451-9.

17. Shatila F, Yusef H, Holail H. Pigment production by Exiguobacterium aurantiacum $\mathrm{FH}$, a novel Lebanese strain. Int J Curr Microbiol Appl Sci 2013;2(12):176-91.
18. Awah FM, Verla AW. Antioxidant activity, nitric oxide scavenging activity and phenolic contents of Ocimum gratissimum leaf extract. J Med Plants Res 2010;4(24):2479-87.

19. Parul R, Kundu SK, Saha P. In vitro nitric oxide scavenging activity of methanol extracts of three Bangladeshi medicinal plants. Pharma innovation 2012;1(12):83-8.

20. Iheanyichukwu W, Francis AM, Modo Emmanuel U, Ruth AO. Evaluation of free radical scavenging capability of Telfairia occidentalis (UGU) and Pterocarpus soyavxii (OHA) ethanolic leaf extracts. Int J Chem Stud 2018;2(2):78-81.

21. Edgar RC. MUSCLE: multiple sequence alignment with high accuracy and high throughout. Nucleic Acids Res 2004;32(5):1792-7.

22. Panda A, Ahuja R, Shastry SS. Comparison of topical $0.3 \%$ of ofloxacin with fortified tobramycin and fortified tobramycin and fortified cephazolin in treatment of bacterial keratitis. Eye 1999;13:744-7.

23. Srinivasan M, Gonzales CA, George C, Cevallos V, Mascarenhas JM, Asokan B, et al. Epidemiology and aetiological diagnosis of corneal ulceration in Madurai, South India. Br J Ophthalmol 1997;81(11):965-71.

24. Maske R, Hill JC, Oliver SP. Management of bacterial corneal ulcers Br J Ophthalmol 1986;70(3):199-201.

25. Narsani AK, Jatoi SM, Lohana MK, Dabir SA, Gul S, Khanzada MA. Hospital-base epidemiology, risk factors and microbiological diagnosis of bacterial corneal ulcer. Int J Ophthalmol 2009;2(4):362-6.

26. Daroy MLG, Lopez JS, Torres BCL, Loy MJ, Tuano PMC, Matias RR. Identification of unknown ocular pathogens in clinically suspected eye infections using ribosomal RNA gene sequence analysis. Clin Microbiol Infect 2011;17:776-9.

27. Saviola B. Pigments and pathogenesis. J Mycobac Dis 2014;4:5.

28. Liu GY, Nizet V. Color me bad: microbial pigments as virulence factors. Trends Microbiol 2009;17(9):406-13.

29. Finlayson EA, Brown PD. Comparison of antibiotic resistance and virulence factors in pigmented and non-pigmented Pseudomonas aeruginosa. West Indian Med J 2011;60(1):24-32.

30. Kirienko NV, Ausubel FM, Ruvkun G. Mitophagy confers resistance to siderophore mediated killing by Pseudomonas aeruginosa. Proc Natl Acad Sci U S A 2015;112(6):1821-6.

31. Kirienko NV, Kirienko DR, Larkins-Ford J, Wählby C, Ruvkun G, Ausubel FM. Pseudomonas aeruginosa disrupts Caenorhabditis elegans iron homeostasis, causing a hypoxic response and death. Cell Host Microbe 2013;13(4):406-16.

32. Balraj J, Pannerselvam K, Jayaraman A. Isolation of pigmented marine bacteria Exiguobacterium sp. From peninsular region of India and a study on biological activity of purified pigment. Int J Sci Technol Res 2014;3(3):375-84.

\section{How to cite this article:}

Jain D. Pseudomonas gessardii-A novel pathogenic bacterium associated with the cases of corneal ulcers and producing virulent pyoverdine pigment. J Appl Biol Biotech 2022; 10(02):68-73. 